\title{
Risk Factors of Dementia in Elderly at Nursing Home
}

\author{
Lisna Anisa Fitriana*, Slamet Rohaedi, Sri Sumartini, \\ Linda Amalia \\ Nursing Department \\ Universitas Pendidikan Indonesia \\ Bandung, Indonesia \\ *lisna@upi.edu
}

\author{
Lilis Komariyah \\ Department of Sport Education \\ Universitas Pendidikan Indonesia \\ Bandung, Indonesia \\ liliskomariyah9@gmail.com
}

\begin{abstract}
Dementia is a deficit of intellectual function, including language disorders, cognition, personality, visuospatial skills and memories of daily activities. The purposed of this study is to identify the risk factors of dementia in elderly at nursing home. The research design used is correlative descriptive with purposive sampling technique to 58 elderly dementia patients in nursing home in Bandung. Univariate analysis using proportion and bivariate analysis using Chi-Square test to determine the relationship between risk factors with dementia. Risk factors consist of age, education, gender, and history of disease. The result showed that as many as $\mathbf{6 7 . 2 \%}$ in the age group of $\mathbf{7 5 - 9 0}$ years old, $41.4 \%$ had elementary school, $84.5 \%$ of them are female, and $\mathbf{6 5 . 5 \%}$ had hypertension. Bivariate analysis found a relationship between age, education, gender, and hypertension with dementia $(p<0.05)$. It can be concluded that age, education, gender, and hypertension contributed to dementia.
\end{abstract}

Keywords-component; dementia; elderly; internal and external factor

\section{INTRODUCTION}

Dementia is a syndrome that is associated with a decrease in the ability of brain functions, such as reduced memory, decreased ability to think, understand something, consider, and understand language, and decreased mental intelligence. This syndrome generally attacks older people over 65 years. Dementia sufferers generally will experience depression, changes in mood and behaviour, difficulty socializing, until hallucinating. Patients are unable to live independently and need the support of others [1].

Dementia has a great impact on family, community, and society for its nursing and expense. The cost that had been expensed in 2015 in Indonesia was 2,2 trillion rupiahs. The cost was distributed $44 \%$ for health care, $21 \%$ for social care, and $35 \%$ for informal care [2]. Unfortunately, dementia or known as forgetfulness is seen as a common thing in elderlies. Meanwhile, dementia itself can be predicted and prevented earlier.

Risk factors of dementia involve modifiable risk and unmodifiable risk. The unmodifiable risk includes age, gender, family background, and genetic factor. Meanwhile, the modifiable risk includes cardiovascular risks (hypertension, hypercholesterolemia, diabetic mellitus, and stroke) and life style changing (diet, sport, etc.) [3]. Other risk factors include obesity, less physical activity, smoking, alcohol consumption, hypertension, stress, hearth problem, stroke, diabetic type 2, cholesterol, high homocysteine, thyroid hormone problem, and vitamin B12, vitamin D, and follicle acid deficiency [4]. Educational background also has a great influence on dementia (Beta $=0,258)$ [5]. Therefore, this study was aimed at discovering the dementia level and its contributing factors on elderlies in nursing home.

\section{METHOD}

The subjects participated in the study were the subjects who met the age criteria ( $\geq 60$-year-old), were able to communicate, were not in severe mental and physical illness, and lived in nursing home. The study took place at Budi Pertiwi and Senjarawi nursing home, Bandung. Fivety-eight of seventynine elderlies who were willing to participate in the study met the above criteria.

This study followed the ethical code from Helsinki Declaration by asking an informed consent to the respondents. The data collection instrument of the study was questionnaire containing questions which were divided into three sections. The first section included respondents' identities such as name, age, gender, education, and marital status. The second section involved health condition and medical history. The third section contained dementia examination by using MMSE (Mini Mental State Examination) which contains 30 questions with three dementia levels of scoring: 21-26 (mild dementia), 16-20 (moderate dementia), 10-15 (moderate-severe dementia), and 0-9 (severe dementia) [3]. The data collection method was also conducted through interviewing respondents and nursing home staffs/caregiver. The obtained data were then analysed through univariate and bivariate analysis. Univariate test was used to draw frequency distribution of each variable. Meanwhile, bivariate test was used to analyse intervariable relationship by using chi-square.

\section{RESULTS AND DISCUSSION}

TABLE I. DEMENTIA ON ELDERLIES IN BUdi PERTIWI AND SENJARAWI NURSING HOME $(\mathrm{N}=58)$

\begin{tabular}{|c|c|c|c|}
\hline \multirow{2}{*}{ Characteristics } & Category & $\mathbf{n}$ & Percentage \\
\hline \multirow{3}{*}{ Dementia (MMSE) } & Mild & 30 & $51.7 \%$ \\
\cline { 2 - 4 } & Moderate & 21 & $36.2 \%$ \\
\cline { 2 - 4 } & Moderate-Severe & 7 & $12.1 \%$ \\
\hline
\end{tabular}


Table 1 shows that most of the respondents, 30 persons $(51.7 \%)$, were in mild dementia category, 21 persons $(36.2 \%)$ were in moderate dementia category, and 7 persons $(12.1 \%)$ were in moderate-severe dementia category. The case of severe dementia was not found during the research as the inability to communicate during MMSE and interview did not occur.

TABLE II. THE DISTRIBUTION OF ELDERLIES' CHARACTERISTICS AND THEIR RELATIONSHIP WITH DEMENTIA IN BUDI PERTIWI AND SENJARAWI NURSING HOME $(\mathrm{N}=58)$

\begin{tabular}{|l|l|l|l|l|}
\hline Characteristics & \multicolumn{1}{|c|}{ Category } & \multicolumn{1}{c|}{ n } & Percentage & $\begin{array}{c}\text { p- } \\
\text { value }\end{array}$ \\
\hline \multirow{3}{*}{ Age } & 60-74 years & 16 & $27.6 \%$ & $0.033^{*}$ \\
\cline { 2 - 5 } & $75-90$ years & 39 & $67.2 \%$ & \\
\cline { 2 - 5 } & $>90$ years & 3 & $5.2 \%$ & \\
\hline \multirow{3}{*}{ Gender } & Female & 49 & $84.5 \%$ & $0.021^{*}$ \\
\cline { 2 - 5 } & Male & 9 & $15.5 \%$ & \\
\hline Background & None & 11 & $19.0 \%$ & $0.015^{*}$ \\
\cline { 2 - 5 } & Elementary School & 24 & $41.4 \%$ & \\
\cline { 2 - 5 } & Junior High School & 9 & $15.5 \%$ & \\
\cline { 2 - 5 } & Senior High School & 12 & $20.7 \%$ & \\
\cline { 2 - 5 } & Diplom & 2 & $3.4 \%$ & \\
\hline \multirow{3}{*}{ Hypertension } & Yes & 38 & $65.5 \%$ & $0.036^{*}$ \\
\cline { 2 - 5 } & No & 20 & $34,5 \%$ & \\
\hline
\end{tabular}

Table 2 presents that most of the respondents, 39 persons (67.2\%), were belonged to 75-90 years age category and were related to dementia $(\mathrm{p}=0.033)$. For gender characteristic, 49 persons $(84.5 \%)$ were female and were related to dementia $(\mathrm{p}=0.021)$. For educational background criteria, 24 persons $(41.4 \%)$ were belonged to elementary school and were related to dementia $(\mathrm{p}=0.015)$. For hypertension history, 38 persons $(65.5 \%)$ suffered from hypertension disease and related to dementia $(\mathrm{p}=0.036)$.

The result of the study showed that the number of elderlies facing mild dementia were higher than elderlies facing moderate dementia. It was influenced by age, gender, and educational background of the elderlies in the Budi Pertiwi and Senjarawi Nursing Home, Bandung. Most of the elderlies were in age 75-90 (old) category. It is in line with the research that in the age of $\geq 70$ years, a person had 88 times possibility to suffer from dementia than elderlies in age 60-69 category [6]. The risk of dementia increases two times higher every five years in $>65$ years age category with $\mathrm{OR}=1.1$ [3]. This is in line with the research that $70 \%$ of persons in age 75-90 experience cognitive impairment, $73.1 \%$ experience probable cognitive impairment and $9.6 \%$ experience definite cognitive impairment [7]. Aging is the cause of the decrease in organ function including brain, where neurons including axon and dendrite suffered from atrophy as well as neurotransmitters in brain such as acetylcholine, GABA, citokine, and nerve development factor, such as IGF-1 and BDNF, that decrease in function, so that dementia happens.

Table 2 shows that gender had a correlation with dementia. It is caused by life expectancy of female is longer than male. Besides that, cognitive function is influenced by estrogen and progesterone hormone, where elderlies who were in menopause period experience the decrease in estrogen and progesterone hormone causing cognitive impairment or dementia. The relationship between the risk of dementia and the number of children, miscarriage, first menstrual age, menopause age, and productive period in 14.595 women age 40-55 shows that women with three children or more have $12 \%$ lower risk to suffer from dementia than women with one child. Besides that, miscarriage has a correlation with the increase of the risk of dementia for about $9 \%$ than women that do not experience miscarriage. The average age of first menstrual period is age 13 years old and the average age of menopause is age 47 years old. Respondents who got the first menstrual period at age 16 years old or over, got $31 \%$ higher risk of dementia. Respondents who got menopause at age 45 years old or below had $28 \%$ higher risk of dementia than those who got menopause over age 45 years old. The average period of productive age is 34 years. The 21-30 years productive period has $33 \%$ higher risk of dementia in compare with 38-44 years productive period [8]. However, further study related to the mechanism between reproduction and brain health is needed. Moreover, the conditions are in line with the conditions of the elderlies in Budi Pertiwi and Senjarawi nursing home who chose to live in nursing home because they did not have any children, or they didn't want to be a burden to their children or another family member. Another reason was the conflict with child in law, so they chose to live in nursing home.

Based on educational background risk factor, the findings showed that the lower the education level, the higher the risk of dementia was. This is in in line with the research that $45.8 \%$ respondents with primary education level educational background obtained 17-23 MMSE score [7]. Cognitive impairment is related to the level of education background of a person [9]. Elderlies with lower educational background had 4 times higher risk of dementia in compare with elderlies with higher level of educational background [10]. Education influences one's cognitive function to take decision, to do computation, and to set a plan [11]. Therefore, when people pursue a higher education, they could maintain their brain function better.

Table 2 also presents that there is had correlation between hypertension and dementia. The study of kohort in 51,580 patients age 20-99 showed that dementia risk in diabetic mellitus patients is higher with hazard ratio $(\mathrm{HR})=1.47,95 \%$ $\mathrm{CI}=1.30-1.67, \mathrm{p}<0.001$ because of the hyperglicemia condition. The risk of dementia did not increase significantly on patients who had only hyperlipidemia $(\mathrm{p}=0.187)$ or hypertension $(\mathrm{HR}=1.22,95 \% \mathrm{CI}=1.05=1.40, \mathrm{p}=0.008)$ [12]. The $25-30 \%$ of ischemic stroke survivors develop immediate or delayed vascular cognitive impairment (VCI) or vascular dementia (VaD) [13]. Multifactorial risk factors for cognitive impairment and dementia after stroke include family history, genetic variants, older age, low educational status, vascular comorbidities, prior transient ischemic attack or recurrent stroke, and depressive illness. Dementia neuroimaging determinants after stroke encompass white matter changes, silent brain infarcts, lacunar infarcts, and medial temporal lobe atrophy.

The result of the research showed that cognitive deficit was associated with stroke, physical inactivity, advanced age, and low body mass index $(p<0.05)$ [14]. Moreover, in patients with dementia, the circle of Willis atherosclerosis was greater than in controls on univariate analysis $(\mathrm{p}=0.01)$. However, when it is 
adjusted with age and gender, this association lost its significance $(\mathrm{p}=0.61)$. Furthermore, in the control group, heart failure and anatomy pathological cardiac parameters were more severe than in demented individuals $(\mathrm{p}<0.05)$.

\section{CONCLUSION}

The result of this study concludes that age, educational background, gender, and hypertension history have an influence on dementia on elderlies living in nursing home $(\mathrm{p}<0,05)$. This study suggests to conduct further studies related to other factors related to dementia, such as independency, family support, loneliness, depression, and dementia history in family. Elderlies in Senjawari and Budi Pertiwi nursing home suffered from $>2$ medical problems in their medical history caused by age factor. Therefore, it is better to conduct further research based on a specific health problem that could have an impact on dementia.

\section{ACKNOWLEDGMENT}

The research was supported by fund of Universitas Pendidikan Indonesia, Bandung.

\section{REFERENCES}

[1] National Dementia Australia, "What is dementia?" 2018. [Online]. Retrieved from: https://www.dementia.org.au/information/aboutdementia

[2] R.M. Theresa, "Prevent dementia with poco-poco exercise," Program book 20th Asia Pacific Regional Conference Alzheimer's Disease International, November 2017.

[3] Indonesian Neurologist Association, "Clinical Practice Guide, Diagnosis and Management of Dementia in the Indonesian Neurologists Association," 2015. [Online]. Retrieved from: http://www.perdossi.or.id
[4] Alzheimer's Indonesia, "Dementia: a life-cycle approach," 2017 [Online]. Retrieved from: https://www.alzi.or.id

[5] R.S. Maryam, T. Hartini and Sumijatun, "The correlation between education degree and activity daily living with dementia among elderly at nursing home," 2015.

[6] D.F. Hidayaty, The correlation of physical and cognitive activity on dementia in elderly in south sukabumi. Jakarta: Thesis, Faculty of Medicine and Health Sciences, UIN Syarif Hidayatullah Jakarta, 2012.

[7] I.G.A.H. Sundariyati, N. Ratep, and W. Westa, "Factors that affect the cognitive states in elderly at kubu public health centre II working place january-february," 2014

[8] AAIC, "Pregnancy and reproductive history may impact dementia risk plus, the moveto re-think the impact of hormone therapy on cognition," [Online]. Retrieved from: www.alz.org/aaic/release 2018/AAIC18Mon-women-dementia-risk.asp

[9] B. Kaur, D.J. Harvey, C.S. DeCarli, L. Zhang, M.N. Sabbagh, and J.M. Olichney, "Extrapyramidal signs by dementia severity in alzheimer's disease and dementia with lewy bodies," Alzheimer Dis Assoc Disord, vol. 27, no. (3), pp. 226-232, 2013.

[10] E. Yudhanti, and Suratini, "Correlation of physical activity with dementia in elderly in balai pelayanan sosial tresna werdha yogyakarta unit budi luhur, thesis, Faculty of health science," Yogyakarta: Aisyah University of Yogyakarta, 2016.

[11] N. Khasanah, and M. Ardiansyah, "The correlation between level of education with cognitive decline in elderly," Mutiara Medika, vol. 12, no. 3, pp. 150-154, 2012.

[12] Y.C. Fun, J.L. Hsu, H.Y. Tung, C.C. Chou, and C.H. Bay, "Increased dementia risk predominantly in diabetes mellitus rather than in hypertension or hyperlipidemia: a population-based cohort study," Alzheimers Res Ther, 2017.

[13] R.N. Kalaria, R. Akinyemi, and M. Ihara, "Stroke injury, cognitive impairment and vascular dementia," Biochim Biophys Acta, vol. 1862, no. (5), pp. 915-925, 2016.

[14] C.K. Soemoto, R.E. Ferretti, L.T. Grinberg, K.C. de Oliveira, J.M. Farfel, R.E.P. Leite, R. Nitrini, W.J. Filho, C.A. Pasqualucci, and Brazilian Aging Brain Study Group, "Association between cardiovascular disease and dementia," Dement Neuropsychol, vol. 3, no. (4), pp. 308-314, 2009. 